\title{
Can policies help schools affirm gender diversity? A policy archaeology of transgender-inclusive policies in California schools
}

\author{
Abstract: \\ Since 2010, California passed three laws that address the safety and inclusion of \\ transgender students. Seth's Law (SB 48), the Fair, Accurate, Inclusive, and \\ Respectful (FAIR) Education Act (AB 9) and The School Success and Opportunity \\ Act (AB 1266). The policies of 10 large urban districts in and around the San \\ Francisco Bay Area were analysed using policy archaeology methodology (PAM) \\ to critically evaluate the possibilities and limits of transgender-inclusive policies to \\ support and affirm gender-diverse (transgender, agender, non-binary, etc.) \\ students. The analysis presented here aims to trouble the normalizing categories of \\ the gender binary that get reified in these policies and offers additional ways to \\ create schools that are more affirming and supportive of all forms of gender \\ diversity.
}

Keywords (5): transgender, policy studies, North America, bullying, harassment, discrimination

Word count: 8892

Funding Details: This paper has been made possible with funding from the Social Science Research Council of Canada (SSHRC) for a study entitled: Supporting transgender and gender minority youth in the school system: Investigating policy and practice.

Acknowledgements: We would like to thank Wayne Martino, the Principal Investigator on the grant that supported this work as well as our community partners who served as the Advisory Board for this project.

Geolocation information: United States, California 


\section{Can policies help schools affirm gender diversity? A policy archaeology of transgender-inclusive policies in California schools}

\section{Introduction}

Eighteen-year-old Gavin Grimm spent most of his high school years fighting to use the bathroom. For most children, using the bathroom at school is an unremarkable event, but for Gavin, it became a battle that consumed three years of his life, and took him all the way to the Supreme Court of the United States. In February 2017 actress and activist Laverne Cox called on the audience at the Grammy Awards to "Google Gavin Grimm," making his case arguably the most high-profile case of its kind in the United States. As a transgender boy, Gavin's experience at school is not unique. Across the nation, children whose bodies do not easily conform to a medically-based dichotomy of male/female gender, or whose ways of expressing themselves defy popular ideology of what it means to be and act like a boy or a girl, are often confronted by schools that are ill-equipped to support them. Some school administrators and district officials may want to be supportive, but lack awareness or experience in cultivating trans-inclusive schools; while other school districts, like Gavin's, are actively hostile toward the bodies of transgender, non-binary, and gender non-conforming youth1, and their ways of expressing their genders. On March 6, 2017, the Supreme Court of the United States vacated the case of Gavin Grimm versus the Gloucester County School Board in Virginia, leaving the question of how best to fully include and support transgender students largely to the states. A few months later, in May 2017, the Seventh Circuit Court of Appeals issued a unanimous decision that allowed Ash Whitaker, another transgender boy, access to boys' bathrooms at school. The decision recognized transgender students 
as protected by Title IX and the Equal Protection Clause of the Fourteenth Amendment to the U.S. Constitution ("Whitaker v. Kenosha Unified School District" 2017). Although this decision most directly impacts students in Wisconsin, Illinois, and Indiana, it provides legal rationale for other courts to interpret Title IX and the Equal Protection Act more expansively. In California, there have been laws passed to ensure that transgender students are treated fairly in schools.

Since 2010, California has passed three laws that address the safety and inclusion of transgender students. Seth's Law (AB 9) (Ammiano 2011) requires schools to strengthen their anti-bullying policies; the Fair, Accurate, Inclusive, and Respectful (FAIR) Education Act (SB 48) (Leno 2011) requires the inclusion of the history and contributions of lesbian, gay, bisexual, and transgender (LGBT) people in the curriculum. The School Success and Opportunity Act (AB 1266) (Ammiano 2015), clarifies the existing state law regarding protections for transgender students in K-12 public schools. As the only state in the U.S. with this set of LGBT-inclusive laws impacting schools, California provides a valuable case for examining how policy reforms aimed at improving school environments may shape the institutional legibility of trans-ness, the material conditions of trans life in schools, and the limits of these policies. In this paper, we explore policy efforts made toward creating more trans-inclusive school spaces in California and the limits of policy-based reforms.

Schooling, Trans Bodies, and the Limits of Policy Reform No policy can fully encapsulate the complexity of human life. As trans scholars and activists have often pointed out (Clare 2017; binaohan 2014; Ellison 2017; Serano 
2007) there is simply no singular definition of "transgender." When institutions develop policy in the name of trans inclusion, they run the risk of simultaneously codifying what it means to be trans and limiting whose gender expression may be protected by such policies. Critical trans legal scholar Dean Spade (2011) argues that this reveals the limits of law, writing that "administrative systems that classify people actually invent and produce meaning for the categories they administer, and ... those categories manage both the population and the distribution of security and vulnerability" (p. 32). This categorical definition may lead to the creation of a "charmed circle" (Rubin 1984/1993) that stratifies whose bodies and ways-of-being are legible and acceptable within the given institution, and whose are not. Paisley Currah (2006), a transgender studies scholar whose work examines the construction of the transgender rights movement, writes that these liberal rights-based frameworks can make class and economic disparity invisible:

In dozens of jurisdictions in the United States, transgender people can make a claim of discrimination if they were denied a place to live because of their gender identity or expression, but not because of their poverty.... taking the legal structures as we find them, not as they ought to be, transgender rights advocates have pursued reformist goals, seeking state recognition of the self-identified gender identity of trans people and working to end the use of gender norms as a criterion in distributing rights and resources (p. 6-7).

Put simply, Currah contends that the trans rights movement "might be described as an identity politics movement that seeks the dissolution of the very category under which it is organized" (p.24). Political scientist Heath Fogg Davis (2017) has questioned whether sex categories are actually necessary in most public systems, arguing that they frequently become mechanisms for exclusion. Davis suggests that rather than creating new sex and 
gender categories, we might be better off with dramatically fewer policies that rely on sex-classification (p.17). Indeed, Spade (2011), building from Critical Race Theory and disability studies, argues that rights-based legal recognition and inclusion are often not actually beneficial to trans people of color, immigrants, those with disabilities, and others who suffer the most structural violence and harm. Instead, he suggests, goals of formal legal equality "undermine the disruptive potential of trans resistance" and threaten alliances built across systems of social stratification like race, class, and ability.

These critiques by trans studies scholars align with a form of policy analysis that Scheurich calls Policy Archaeology Methodology (PAM) (1994) which seeks to examine social problems and proposed policy solutions through a Foucauldian lens. This approach helps us understand how certain social "problems" get identified and constructed within existing "grids of social regularity" (p. 301) and result in a certain set of policy solutions that reify and naturalize the framing and naming of such problems. While K-12 school policy that focuses on trans inclusion is billed as a way of improving the circumstances of trans young people, it may be limited in achieving that goal beyond the rhetorical level. Such policy, which is not typically written by or developed in consultation with trans people themselves, is often based on a narrow conception of what it might mean to be a trans child or teen, one that is seen only through the lens of a normative dichotomous gender binary, or which fails to account for race and other institutionalized forms of categorization that shape the life of an individual (Brockenbrough and Boatwright 2013; Frohard-Dourlent 2016; Ingrey 2012; Keenan 2017; Marquez and Brockenbrough 2015; Stiegler 2016). 
These inadequacies have implications for the practical realities of schools, and shape how young people's bodies and (inter)actions are understood. For example, in their analysis of litigation of school-based harassment cases, Marquez \& Brockenbrough (2013) illustrate ways in which law and policy can be used to interpret situations exclusively as homophobia, without full consideration of White supremacy, racial difference, and femiphobia. Thus, they question whether anti-discrimination policy "can benefit all students equally if those students are positioned differently within schools and society" (p. 475). Further, they argue that this type of policy risks constructing a trans subject that is “ostensibly White and middle class." C. Riley Snorton's (2017) recent book on the intersections of Blackness and transness also emphasizes how the normative trans subject has been historically constructed through antiblackness. These critiques are an important frame through which to examine the two high-profile cases of Gavin Grimm and Ash Whitaker noted in the introduction. These cases, which both involve white transmasculine youth, largely focus on gender as an isolated social category. Here, the legal system is set up such that, beyond the control of the individuals struggling to find ways to meet their needs, impact litigation aims to set legal precedent that will lead to broader social change. Thus, their publicity and translation into school policy simultaneously serves as a form of popular pedagogy. These widespread impacts can risk deepening public ideology and institutional governance that fail to account for multiple vectors of structural oppression.

School policies and practices aimed at "safety" and "inclusion" for marginalized students often seek to achieve these goals primarily through the regulation and punishment of individual behaviour, rather than changing the institutional conditions that 
produce normative systems of gender: the dichotimization of sex categories by medical and scientific systems (Fausto-Sterling 2000), the gender binary (Bem 1993), and the heterosexual matrix (Butler 1990). These systems work together to create dominant understandings of an idealized "normal" body that is simultaneously sorted into hierarchies of race, class, and ability. In other words, policy can perpetuate the very harm it purportedly seeks to erase by reproducing systems of stratification. Walton (2010) builds on Scheurich's work and refers to this dilemma as the "problem trap," explaining that "for much of the public, such efforts look good because they appear to address the moral panic of youth violence through policy regulation" (p.148). For Walton and Scheurich, how the problem is defined dictates how the problem is understood and addressed by institutions and individuals within those systems. What might policies on trans inclusion actually do for trans people, and others who challenge rigidly-defined concepts of binary gender? Here, we are interested in how school policy frames trans experience, and consider how its framing may impact the material conditions of gender and trans life in schools.

Legal and political context in the United States

In addition to providing valuable context to our study, the example of Title IX and how sex is defined and interpreted provides a helpful case study to better understand the limits of legal and policy reforms to address social issues by providing recognition and protection for gender-diverse students. In the United States, the federal legislation Title IX, enforced by the Office for Civil Rights in the U.S. Department of Education (DOE) and the U. S. Department of Justice (DOJ), has often been used in efforts to challenge discrimination experienced by transgender youth in schools. In 2016, the DOJ and DOE 
issued a "Dear Colleague Letter on Transgender Students" (Lhamon and Gupta 2016). This letter was written to provide "significant guidance" by providing information and examples about complying with legal obligations. In the letter, the DOJ and DOE clarified the purpose of Title IX of the Education Amendments of 1972 to prohibit sex discrimination in federally-funded educational programs and activities. The authors stated that "this prohibition encompasses discrimination based on a student's gender identity, including discrimination based on a student's transgender status" (p. 1). The letter provided explicit examples by stating, "A school's Title IX obligation to ensure nondiscrimination on the basis of sex requires schools to provide transgender students equal access to educational programs and activities even in circumstances in which other students, parents, or community members raise objections or concerns" (p. 2) and that they “...must allow transgender students access to such facilities consistent with their gender identity" (p. 3). While this guidance provided visibility for transgender students within the law and a set of flexible principles for schools to apply in context, it generated significant resistance and placed transgender students' lives in the cross-hairs of a very public culture war.

In response to this letter, on May 24, 2016 eleven2 states filed a lawsuit challenging the federal guidance (Berman and Balingit 2016) and on July 8, 2016 ten3 more states joined the suit (Emma 2016). Later that summer, on August 21, 2016 U. S. District Judge Reed O'Connor of Texas granted a preliminary nationwide injunction which meant the guidance issued in May 2016 by the Office for Civil Rights (OCR) was not enforceable (Domonoske 2016). In the lawsuit, the plaintiffs argue that "sex" means only "biological sex" 4 . The judge granted the injunction stating that, "the administration 
didn't follow the proper notice and comment process for guidelines" and that the term "sex" in Title IX meant "the biological and anatomical differences between male and female students as determined at their birth" (p. 2). He also stated that any "definition of sex that included gender identity" should not be the basis of any sort of Title IX investigation. This demonstrates the ways in which certain categories of protection continue to be contested and interpreted in the courts. The fact that an individual must somehow fit neatly within a prescribed legal category in order to secure the protections of the law does not provide meaningful supports for individuals whose identities transcend and blend discrete legal categories as argued by Kimberlé Crenshaw (1991) in her foundational work on intersectionality and Critical Race Theory.

While the courts debate whether the genders of trans youth are legally "real," trans youth across the United States suffer from the stratified material conditions created by administrative systems that manage the distribution of security and vulnerability (Spade 2011). Since the definition of "sex" under Title IX is still being debated, who gets to seek protection from discrimination under this law is up for continued contestation. In the meantime, trans youth often do not get the supports they need to fully participate in school life. Thus, state laws and school district policies that focus on transgender students are worthy of examination.

\section{Legal and political context in California}

California has long been considered a leader in the area of activism and legal recognition of rights and protections for lesbian, gay, bisexual, and transgender communities, and these efforts are reflected in the state's public schools. While this legislative change has been publicly lauded for making schools more inclusive, much of 
its focus has been on how to respond to individual students. The problem with creating solutions that individualize a problem and focus on individualized solutions (punishments, responses, accommodations) have been critiqued by anti-bullying scholars (Walton 2004, 2005; Meyer 2008) as insufficient and temporary solutions to systemic and ongoing issues. Rather than changing the conditions that marginalize trans students and lead to their suffering in schools, these legislative efforts focus primarily on two things: (1) the expansion of anti-bullying and non-discrimination measures which explicitly name mistreatment based on gender or sexual orientation as punishable offenses and (2) the creation of administrative channels for trans students to make themselves legible within the system.

Starting in 2000, the legislature passed the California Student Safety and Violence Prevention Act5 (AB 537, Kuehl), which prohibits discrimination and harassment in schools based on specified categories: sex, ethnic group identification, race, national origin, religion, colour, or mental or physical disability. It also amended the state Education Code by adding actual or perceived sexual orientation and gender identity to existing sections on discrimination. California is one of thirteen states that has nondiscrimination laws protecting K-12 students based on gender identity and sexual orientation (GLSEN 2014). In 2007, The Safe Place to Learn Act (AB 394, Levine), and the Student Civil Rights Act (SB 777, Kuehl) were passed. These laws require the California Department of Education to monitor school districts' creation and publication of anti-harassment policies and complaint procedures, as well as adding to the list of prohibited bases of discrimination and harassment.

In 2011, the passage of Seth's Law (AB 9) delineated steps to strengthen and 
clarify existing anti-bullying and non-discrimination laws. One addition of this law is the requirement for each school district to include in its non-discrimination policy an enumerated list of the bases on which discrimination, harassment, intimidation, and bullying are prohibited under existing law. The list consists of nine categories including: actual or perceived sexual orientation, gender, gender identity, gender expression, race or ethnicity, nationality, religion, disability, or association with a person or group with one or more of these actual or perceived characteristics. Even though this language is present in the state Education Code, the requirement that each category be listed in district documents is designed to help clarify protections at the local level. Seth's Law also requires schools to include more detail in their complaint procedures including: a) a clear method for receiving and investigating discrimination and harassment complaints, b) acting on discrimination and harassment complaints expeditiously so that investigation and resolution may be reached quickly, and c) faculty and staff working on school campuses would be required to intervene when they witness acts of bullying if it is safe to do so. This bullying law spells out specific expectations for districts and educators about their roles and responsibilities in intervening, reporting, investigating, and resolving incidents of bullying and harassment.

Two years after Seth's Law was passed, the School Success and Opportunity Act (AB 1266)6 was signed (2013) and took effect on January 1, 2015. This law clarifies existing protections present in state laws since 2000 (AB 537) and how they apply to transgender students in K-12 public schools. It states: "A pupil shall be permitted to participate in sex-segregated school programs and activities, including athletic teams and competitions and use facilities consistent with his or her gender identity, irrespective of 
the gender listed on the pupil's records."

The San Francisco Bay Area is a unique political context in which to be investigating school policy surrounding trans students due to its longstanding reputation as an LGBT community hub (D'Emilio 1989; Armstrong 2002). Recently, San Francisco City Supervisor Jane Kim declared plans to develop the first transgender cultural district in the Tenderloin in the neighbourhood where Compton's Cafeteria sits, a site of early transgender activism and resistance to police actions pre-dating the Stonewall riots in New York City (Keeling 2017). Meanwhile, the Bay Area is simultaneously experiencing rapid gentrification, leading to skyrocketing housing costs in San Francisco that have pushed many low-income residents, predominantly Black and Latinx, further and further away from the urban center. While poor Black and Latinx trans women of the 1960s are being rhetorically celebrated as activist heroes in the Tenderloin, trans women of color living in poverty are increasingly being pushed out of the city. Because of their direct implications for the demographics and lived realities of student bodies in schools, the material conditions of wealth disparity and the remaking of what sociologist Ryan Centner (2008) refers to as "spatial capital" in San Francisco are inseparable from any exploration of institutional marginalization within Bay Area schools. In part, this frames our analysis by presenting evidence that current policy does little to improve the living conditions of those trans people who are most severely impacted by structural violence and harm.

\section{Methods and data sources}

This research employs content analysis (Hsieh and Shannon 2005; Bengtsson 
2016) and policy archaeology methodology (PAM) (Scheurich 1994) to explore the content of policies aimed at trans inclusion by examining: 1) how they frame trans students, 2) what social regularities are shaping the understanding of this "social problem," 3) what solutions are proposed as "acceptable," and what alternatives may exist. The researchers identified the ten largest districts in San Francisco and Alameda Counties for policy analysis, each with over 10,000 students enrolled. The districts included are summarized in Table 1. For each school district, we reviewed three types of policies: non-discrimination policy, anti-bullying/harassment policy, and policies explicitly addressing transgender students. We first conducted a basic content analysis of these policies to map out how they aligned with state laws. We reviewed each district's policy on non-discrimination to see if each of the nine categories listed in Seth's Law were present in the language at the district level. Additionally, each district's antibullying policy was reviewed to see if it incorporated nine key elements from Seth's law (the following letters and numbers correspond to the actual text of the law): (B) Process for complaint: 1) intervention, 2) timely response, 3) appeal process, 4) translated documents available, (C) policy is publicised (D) policy is posted (E) process for documentation of bullying reports, $(\mathrm{F})$ protection from retaliation, $(\mathrm{G})$ complaint officer named, and 234.5) resources on website. Finally, we noted whether each of these ten districts had a policy that explicitly addressed transgender students or not. By assigning a 1 for yes/present and 0 for no/absent, we were able to assign a total score out of 19 ( 9 non-discrimination elements, 9 bullying elements, 1 transgender policy) to each district. Subsequently, the policies were analysed for common language and themes through the PAM lens. 
--insert table 1 about here-

Table 1. School districts included in the analysis, policies reviewed, and dates revised/approved.

\section{Results}

The results of the policy analysis indicate that there is clear disjuncture between school policy and California state law. Only San Francisco Unified School District received a score of 19/19, indicating that their policy reflects all the requirements of the three state laws. The average score was 16.1/19. The categories that were most often missing were related to requirements in Seth's Law. The analysis of the anti-bullying policies indicated that all ten districts had made updates to their policies since Seth's Law came into effect, however several of them were missing required elements. Eight school districts did not list an appeals process, five districts did not have translated versions of relevant documents on their website, and four districts did not specifically mention protecting students from retaliation after reporting. The two districts that had elements missing from their non-discrimination policy omitted the categories of: "gender identity, gender expression, and association with a person or group with one or more of these actual or perceived characteristics". The complete results are summarized in Figure 1. The fact that gender identity and expression were the categories least likely to be named and recognized may reflect the relatively recent emergence of these as protected categories and that they continue to be among the most contested in school communities as noted in the discussion of Title IX above. 
---insert figure 1 about here---

Figure 1. Policy Content Analysis

The analysis of transgender-inclusive policies indicated that only half of these large districts have any sort of policy in place that explicitly addresses transgender youth: the five districts that did have a policy available on their website were Berkeley, Oakland, Hayward, Fremont and San Francisco. We found up to twelve sub-headings used to organize the elements addressed in these policies. These sub-headings include the following areas: non-discrimination (gender identity \& expression), harassment, pronouns, school records, facilities/bathrooms, locker rooms, dress codes, sports \& gym class, yearbook photos, gender segregation (class discussions, field trips, other areas), information \& education for students and/or training for staff (gender identity \& expression), and a transition plan. The most extensive policy was from Fremont Unified School District, which included all of the twelve elements listed above. San Francisco and Oakland each had nine followed by Hayward (6) and Berkeley (5). The three elements that were unique to Fremont are: yearbook photos, information and training for staff and students, and a transition plan.

We want to be clear that a more extensive policy is not inherently a better policy. Having more sub-headings may provide more clarity on certain topics, but excessive detail can become cumbersome to draft, approve, and enact. It also creates a kind of "script" (Keenan 2017) that further defines and restricts the legibility of gender, creating restrictions and unanticipated barriers for non-binary students, and others whose identities and forms of self-expression do not fit neatly into a dichotomous male/female 
gender binary. It also makes an implicit assumption that perhaps the only students likely to struggle with gendered institutional mandates related to things like yearbook photos, dress codes, or locker rooms are those who identify themselves as transgender. In fact, these situations script - and therefore confine - the bodies and actions of all young people through an institutionalized vision of appropriate gender expression, which is simultaneously racialized, classed, and otherwise rooted in notions of which bodies and forms of expression are normal, and which are not. For instance, rather than examining how a gendered dress code confines how all children can express themselves, this policy awaits a student to come forward with a complaint that the school sees as reasonable. This, of course, also requires a student or family who is able to successfully navigate institutional channels and communication and who has sufficient resources to risk such disclosure. Furthermore, the practice of dress codes in U.S. schools is one that is simultaneously highly racialized, historically designed to "encourage docility toward 'rightful authority"' (Brunsma 2004, 5) and to "deculturalize" Indigenous and other students of colour (Spring 2001). With its focus on individual students, this policy does little to change the racialized and gendered conditions of administrative control and regulation.

What may be more productive in drafting policy, is being clear and broad about the spirit in which it is meant to be interpreted and applied. For example, Fremont's policy opens with the following statement,

This regulation does not anticipate every situation that might occur and, therefore, the needs of each student must be assessed on a case-by-case basis. In all cases, the goal under Board Policy 5145.5 is to ensure the safety, comfort, and healthy development of the transgender or gender variant student while maximizing the 
student's social integration into the school setting and minimizing stigmatization of the student.

This statement intends to offer guidance for school administrators to use when having to make individual judgment calls in unique situations, but continues to focus on the "transgender or gender variant student" as the individual who needs to be "integrated" rather than seeing the institution as a site in need of reform, or its own role in producing situations that harm trans people. By explicitly naming the goal of "maximizing the student's social integration" and "minimizing stigmatization", the policy places the emphasis on individual, rather than institutional, adaptation.

Fremont Unified School District's policy includes two sections that are worth discussing more in-depth: a) addressing a student's gender identity and transition needs and b) guidance and training. The "transition needs" section reads as follows:

The school site principal shall arrange a meeting with the student and, if appropriate, his/her parents/guardians to identify potential issues, including gender transitionrelated issues, and to develop strategies for addressing them. The meeting shall discuss the transgender or gender variant student's rights and how those rights may affect and be affected by the rights of other students and shall address specific subjects related to the student's access to facilities, programs, activities, academic or educational support programs or services, including, but not limited to, athletics. In addition, the school site principal shall identify specific school site employee(s) to whom the student may report any problem related to his/her status as a transgender or gender- variant individual, so that prompt action could be taken to address it.

There is some value in having this section clearly explained in order to help parents, families, and administrators know about what has been identified as recommended practices in supporting a student's social transition at school (Orr and Baum 2015; Wells, 
Roberts, and Allan 2012; Luecke 2011). Establishing a support plan and naming key professionals involved in developing and implementing such a plan can provide important institutional supports for a student seeking to transition. However, not all students may seek a social transition as many transgender students do not identify within the male/female binary and such a 'transition plan' implies that is the only recognizable way of being transgender and having one's identity affirmed at school. Even though they use the term 'gender variant' to be more inclusive of gender diversity, this is a term that is not widely used within the transgender community and implies some abnormality or pathology. It also suggests some disjuncture between the policy's authors and the wide array of transgender communities in the Bay Area. Further, there is no guidance for how students who do not conform to the gender binary, and who may not specifically use the language of "transgender" to describe themselves, might be supported in sex-segregated programs or how the school will be changing its structures to be less hostile to gender diversity.

Fremont's policy also goes further than other policies in making recommendations for additional training and guidance for school employees. Although it falls short of mandating regular trainings on this topic, it acknowledges that having "periodic training" for school staff is worth mentioning in formal policy language. However, there are no established goals or criteria for what these trainings will do. Importantly, the quality of these trainings can vary significantly and mandated trainings can often cause resistance and negativity in a school. On the other hand, having these components spelled out in policy may provide some political capital to push for better supports to offer more professional learning opportunities in order to be more fully ready 
to welcome transgender and non-binary students by sharing publicly some of the ways in which this school culture is shifting in order to be more fully inclusive of gender diversity. Other research in this area indicates that families with transgender students often bear a very large burden when they are the first family in a school or district to advocate for the needs of their child (Meyer, Tilland-Stafford, and Airton 2016; Slesaransky-Poe et al. 2013; Meyer and Leonardi 2017). When schools work to disrupt the social regularities that create barriers for transgender youth such as organizing facilities, activities, and rituals based on the gender binary and the heterosexual matrix, it may serve to reduce the number of individual "accommodations" made necessary by a constrictive system, and simultaneously remove barriers for all students, not only those who identify themselves as transgender.

Another interesting item to note is that many of the policies shared similar headings and language that indicate they may have each referenced a common source document. For example, the model policy document produced by GLSEN and the National Center for Transgender Equality (2016) organize their policy using nine headings and the California Safe Schools Coalition (2016) also produced a model policy document that includes twelve slightly different headings. These headings are summarized in Table 2. There were four broad categories present in all three sets of documents examined. These include: (a) non-discrimination and harassment; (b) names, pronouns and school records; (c) dress codes; (d) bathrooms, facilities, and gender segregated activities.

---insert table 2 about here ----

Table 2. Comparison of headings in district and model policies 
These headings align with the two categories we identified earlier: (1) the expansion of anti-bullying and non-discrimination measures which explicitly name mistreatment based on gender or sexual orientation as punishable offenses and (2) the creation of administrative channels for trans and non-binary students to make themselves legible within the system. One likely explanation for this duplication of categories is that San Francisco Unified School District, among the first area districts to create policy aimed at trans inclusion, developed and refined their policy over the years and neighbouring districts developed their own policies based on the existing local model. SFUSD's first policy was adopted in 2003 and updated in 2006, and then updated again after the passage of AB 1266 in 2013. The current policy mostly restates relevant excerpts from the California Educational Code and the California Code of Regulations that apply in the cases of "gender-based discrimination." These elements impact all schools in the state of California and are worth spelling out here to demonstrate how the "problem" and solutions have been framed in state law:

- "all pupils have the right to participate fully in the educational process, free from discrimination and harassment." Cal. Ed. Code Section 201(a).

- The Code further provides that public schools have an affirmative obligation to combat sexism and other forms of bias, and a responsibility to provide equal educational opportunity to all pupils. Cal. Ed. Code Section 201(b).

- California Education Code Section 221.5(f) specifically requires that "A pupil shall be permitted to participate in sex-segregated school programs and activities, including athletic teams and competitions, and use facilities consistent with his or her gender identity, irrespective of the gender listed on the pupil's records."

- The California Code of Regulations defines "gender" as: "a person's actual sex or perceived sex and includes a person's perceived identity, appearance 
or behavior, whether or not that identity, appearance, or behavior is different from that traditionally associated with a person's sex at birth." 5 CCR Section 4910(k).

California Education Code Section 221.5(f) is an example of how the gender binary is established as an official "social regularity" (Scheurich, 1993, p. 300) by assuming every student will have a gender identity that falls within the recognized social categories of "boy" or "girl" around which competitive athletics and facilities have been organized. Agender, gender-fluid, and non-binary students are completely invisible in this regulation as there are few facilities, sports teams, or extracurricular activities designed to include students of any gender. Another element of these policies is that they provide individualized options to students for various forms of accommodation and support, but do not mandate specific solutions or require the institution to make broad changes that will impact the whole school community. In the case of locker rooms, the SFUSD policy explains:

Where available, accommodations may be used by any student who desires increased privacy, regardless of the underlying reason. The use of such accommodations shall be a matter of choice for a student, and no student shall be compelled to use such accommodations. Based on availability and appropriateness to address privacy concerns, such accommodations could include, but are not limited to:

- Use of a private area in the public area (i.e., a bathroom stall with a door, an area separated by a curtain, a PE instructor's office in the locker room);

- A separate changing schedule (either utilizing the locker room before or after other students); or

- Use of a nearby private area (i.e., a nearby restroom, a nurse's office).

While these policies differ from some that require the transgender student to use the more 
private facility, and may be helpful for transgender students who identify within the binary, the accommodations are mostly restricted to changes in individual behaviour and access, not about shifting the structures that create these barriers in the first place. This excerpt is an example of what is often advocated for by organizations working with transgender youth and their families: options for all and restrictions for none (Orr and Baum 2015). Once again, while this approach may provide support for some students, it fails to address the broader conditions that framed this situation as problematic.

SFUSD also provides resources on a website that provides the policy, name change documents, and an FAQ on AB1266 (SFUSD Student Family and Community Support Department 2018b) which makes this information much more accessible to students and their advocates while simultaneously reifying the categories and identities which may be recognized and supported through these policies. The district's website also delineates LGBTQ students' rights and the related district policies, state and federal laws ensuring those rights are respected and upheld (SFUSD Student Family and Community Support Department 2018a). The nine rights included on this district document are as follows:

1. Right to be treated equally and to be free from bullying, harassment and discrimination, regardless of sexual orientation, gender identity or gender expression (SFUSD Board Policy 5162; California Education Code Section 200-220)

2. Right to be respected and to dress and act in ways that do not conform to stereotypes associated with your gender, with respect to the student dress code (SFUSD Board Regulation R5163a; California Education Code Section 221.5) 
3. Right to LGBTQ-inclusive social studies, history and comprehensive sexual health education (California Education Code Section 51204.5, and 5193051939)

4. Right to be referred to by the gender pronoun and name that fits your gender identity (SFUSD Board Regulation R5163a; California Education Code Section 221.5)

5. Right to be involved in school activities, and access spaces such as locker rooms and restrooms, that fit with your gender identity (SFUSD Board Regulation R5163a; California Education Code Section 221.5)

6. Right to speak out about LGBTQ issues, including wearing LGBTQaffirming t-shirts, stickers and bracelets, and access information about LGBTQ issues on school computers, and to bring same gender dates to prom (California Education Code Sections 48907\&48950)

7. Right to form and organize Gay-Straight Alliance, or similarly LGBTQrelated student clubs (Federal Equal Access Act; California Education Code Section 220)

8. Right to be "out" and be yourself at school, and give permission to school staff of when and to whom they can share your LGBTQ identity

9. Right to consent to sensitive LGBTQ or sexual health-related services without permission from your parent/guardian or primary caregiver, if you are age 12 or older (California Health and Safety Code 124260; SB 543; California Family Code 6924)

Here, too, what students should have and be able to do at school is framed through the language of individual rights, rather than institutional responsibility. Rather than declaring that schools must provide access to LGBTQ-competent health care, for example, this list states that students have a right to access this care. Changing the language of this bill of rights to a set of institutional responsibilities (e.g. "Your school has a responsibility to ...”) might offer some small preliminary measure toward greater institutional accountability. 
We are conducting interviews with local key informants and stakeholders to further explore the historical evolution of these policies and the surrounding supports that enabled them to be approved and enacted prior to the passage of AB 1266 in 2014. Preliminary analyses of the interview data illustrate San Francisco Unified School District's long history of efforts toward supporting students' gender and sexual identities. Additionally, the presence of several national advocacy organizations in the Bay Area has created a unique web of supports for transgender students and their families. Data provided by key informants indicate that there are a diverse array of professionals and organizations working to assist schools and families advocating for transgender students and provides an affirming community context for this work. These interviews are currently being analysed and will be the subject of future publications.

\section{Conclusion}

As the question of how to address the needs of transgender students faces schools across the United States and other nations worldwide, schools in California stand at the forefront of policy efforts toward trans inclusion. While elements of these policies may create a pathway for some trans students to access resources and support, they rest upon a model of inclusion that requires institutional legibility and recognition and are primarily focused on the management of individual people and cases rather than institutional change.

As they are based on law, the limitations of school policy aimed at trans inclusion mirror the limits of law. While these policies may be tactically useful to some trans students to successfully navigate administrative channels, they place the responsibility of change primarily on the individual, and do little to change the power of school systems to 
categorize children's bodies or break down a system of script-making for what kinds of gender are normal and which are not (Keenan 2017). In other words, these policies largely task children with leading the process for solving a set of problems that they did not create. There is an emerging body of work beginning to study the experiences and issues faced by transgender, non-binary, and gender-creative students in schools (Ehrensaft 2014; Martino and Cumming-Potvin 2014; Meyer and Pullen Sansfacon 2014; Slesaransky-Poe et al. 2013; Beemyn 2015). However, existing policy has largely been designed without a deep analysis of the layered conditions that shape how schools give meaning to trans and non-binary gender. Without that knowledge, existing policy, like existing law, has largely been created through a lens that frames static, cisgender identity as the norm, a lens that is further shaped by institutionalized assumptions about race, class, and ability.

Further, by framing the conditions of trans life at school outside of the conditions of racialization, immigration, displacement, and wealth disparity in the Bay Area, these policies suggest that the conditions that shape suffering for trans youth in schools can be addressed as a single issue. But, as Audre Lorde (1982/2007) famously wrote, "there is no such thing as a single-issue struggle because we do not live single issue lives." Future studies that allow for the examination of policy enactment within particular school contexts can provide additional insights on ways schools might work toward justice for trans students that more broadly considers the complex conditions of intersecting forms of administrative marginalization and stratification.

While we offer some critiques of the laws and policies in this article, we recognize the value and support that many transgender students have received from the 
laws and policies developed in various regions and argue that in the absence of clear federal guidance, state laws and/or local policies that address gender diversity have perhaps served a tactically useful step to make some trans identities legible in the institutional context of schooling. Given the structure of the US legal system, in which legal redress is individualized, some pathways have been created for some students and families a way to engage with their school administration and seek a more supportive environment. Our critique is not of the individual youth and families who are doing whatever they can to access support and legibility within the systems that give institutionalized meaning to gender. In meeting their most immediate needs, individual actors are forced to work with the system as they find it, no matter whether and how they might wish it were different. Rather, our concern is with systems of school governance themselves, the limitations of policy reform, and the ways in which such reform may deepen or expand systems of stratified resource distribution and channels for redress. We want to push the understanding of what is possible in drafting transgender-inclusive policies. Specifically, we encourage school leaders and community members to critically rethink how they are framing the "problem" of gender diversity in their school communities and seek to make changes that are more universally transformative of restrictive school environments. Simultaneously, we encourage a critical re-examination of existing individualized, temporary solutions that start and end with the known presence of a transgender student. Gender stereotyping, heteronormativity, and cisnormativity, all of which are heavily racialized and classed, are common features of most school communities and have harmful impacts on all students. We seek to create schools that do less rather than more to categorize and define students' bodies for them, and 
which take primary responsibility for supporting students to learn and grow in their full and multidimensional selves. 


\section{References}

Ammiano, T. 2011. "Seth's Law (AB 9)." In, 4. Sacramento, CA.

- 2015. "AB-1266 Pupil rights: sex-segregated school programs and activities." In Chapter 85, edited by California State Legislature, 1. Sacramento, CA.

Armstrong, E. A. 2002. Forging gay identities: Organizing sexuality in San Francisco, 1950-1994. Chicago, IL: University of Chicago Press.

Beemyn, Genny. 2015. "Coloring Outside the Lines of Gender and Sexuality: The Struggle of Nonbinary Students to Be Recognized." The Educational Forum 79 (4):359-61. doi: 10.1080/00131725.2015.1069518.

Bem, Sandra. 1993. The Lenses of Gender: Transforming the Debate on Sexual Inequality. New Haven: Yale University Press.

Bengtsson, Mariette. 2016. "How to plan and perform a qualitative study using content analysis." Nursing Plus Open 2:8-14. doi: https://doi.org/10.1016/j.npls.2016.01.001.

Berman, Mark, and Moriah Balingit. 2016. "Eleven states sue Obama administration over bathroom guidance for transgender students." In Washington Post. Washington D.C.

binaohan, b. . 2014. decolonizing trans/gender 101. Toronto: Biyuti.

Brockenbrough, E., and T. Boatwright. 2013. "In the MAC: Creating safe spaces for transgender youth of color." In Cultural transformations: Youth and pedagogies of possibility, edited by K. Jocson, pp. 165-82. Cambridge, MA: Harvard Education Press.

Brunsma, D. L. . 2004. The school uniform movement and what it tells us about American education: A symbolic crusade. Lanham: Scarecrow Education.

Butler, Judith. 1990. Gender Trouble. New York: Routledge Falmer.

California Safe Schools Coalition. "Model school district policy for transgender and gender nonconforming students."

http://www.casafeschools.org/resourceguide/model-school-district-policytransgender-gender-nonconforming-students/.

Centner, R. . 2008. "Places of privileged consumption practices: Spatial capital, the dotcom habitus, and San Francisco's Internet boom." City \& Community 73 (3):193223.

Clare, E. . 2017. Brilliant imperfection: Grappling with cure. Durham, NC: Duke University Press.

Crenshaw, K. 1991. "Mapping the Margins: Intersectionality, Identity Politics, and Violence against Women of Color." Stanford Law Review 43 (6):1241-99. doi: $\backslash 10.2307 / 1229039$.

Currah, P. . 2006. "Gender pluralisms under the transgender umbrella." In Transgender Rights, edited by Richard M. Juang Paisley Currah, and Shannon Minter. Minneapolis: University of Minnesota Press.

Davis, H.F. 2017. Beyond Trans: Does Gender Matter?. New York: NYU Press.

D'Emilio, John. 1989. "Gay politics and community in San Francisco since World War II." In HIdden from History: Reclaiming the Gay and Lesbian Past, edited by Martin Duberman, Martha Vicinus and George Jr. Chauncey, 456-73. New York, NY: Penguin Books. 
Domonoske, Camila. 2016. "U.S. Judge Grants Nationwide Injunction Blocking White House Transgender Policy." NPR.

Ehrensaft, Diane. 2014. "From gender identity disorder to gender identity creativity: The liberation of gender non-conforming children and youth." In Supporting transgender and gender-creative youth: Schools, families, and communities in action, edited by E. J. Meyer and Annie Pullen Sansfacon, 13-25. New York: Peter Lang.

Ellison, T., Green, K., Richardson, M., \& Snorton, C. R. 2017. "We got issues: Toward a black trans* studies." Transgender Studies Quarterly 4 (2):162-9.

Emma, Caitlin. 2016. "10 more states sue Obama administration over transgender bathroom directive." Politico.

Fausto-Sterling, Anne. 2000. Sexing the Body: Gender Politics and the Construction of Sexuality. New York: Basic Books.

Frohard-Dourlent, H. 2016. ""Muddling through together:" Educators navigating cisnormativity while working with trans and gender-nonconforming students." University of British Columbia.

GLSEN. 2014. "Nondiscrimination laws protecting students by state." Accessed December 2. http://glsen.org/article/state-maps.

GLSEN, and National Center for Transgender Equality. "Model district policy on transgender and gender nonconforming students." GLSEN. https://www.glsen.org/sites/default/files/GLSEN Trans Model Policy 2016_0.pdf.

Hsieh, Hsiu-Fang, and Sarah E. Shannon. 2005. "Three Approaches to Qualitative Content Analysis." Qualitative Health Research 15 (9).

Ingrey, Jennifer C. 2012. "The public school washroom as analytic space for troubling gender: investigating the spatiality of gender through students' self-knowledge." Gender and Education 24 (7):799-817. doi: 10.1080/09540253.2012.721537.

Keeling, Brock. 2017. "Transgender cultural district planned for San Francisco's Tenderloin." Curbed San Francisco.

Keenan, Harper. 2017. "Unscripting Curriculum: Toward a Critical Trans Pedagogy." Harvard Educational Review 87 (4):538-56.

Leno, Mark. 2011. "Fair, Accurate, Inclusive, and Respectful Education Act." In Education Code.

Lhamon, Catherine, and Vanita Gupta. 2016. "Dear Colleague Letter on Transgender Students." In, edited by U.S. Department of Education, 9. Washington, D.C.: U.S. Department of Education, Office for Civil Rights.

Lorde, A. . 1982/2007. "Learning from the 1960s " In Audre Lorde, Sister Outsider: Essays \& Speeches by Audre Lorde, 134-44. Berkeley, CA: Crossing Press.

Luecke, J. C. 2011. "Working with transgender children and their classmates in preadolescence: Just be supportive." Journal of LGBT Youth 8 (2):116-56.

Marquez, Rigoberto, and Ed Brockenbrough. 2015. "Queer Youth v. the State of California: Interrogating Legal Discourses on the Rights of Queer Students of Color." Curriculum Inquiry 43 (4):461-82. doi: 10.1111/curi.12021.

Martino, Wayne, and Wendy Cumming-Potvin. 2014. "Teaching about sexual minorities and "princess boys": a queer and trans-infused approach to investigating LGBTQthemed texts in the elementary school classroom." Discourse: Studies in the Cultural Politics of Education:1-21. doi: 10.1080/01596306.2014.940239. 
Meyer, E. J., and B. Leonardi. 2017. "Teachers' professional learning to affirm transgender, non-binary, and gender-creative youth: Experiences and recommendations from the field " Sex Education. doi: 10.1080/14681811.2017.1411254.

Meyer, E. J., and Annie Pullen Sansfacon. 2014. "Supporting transgender and gendercreative youth: Schools, families, and communities in action." In, edited by E. J. Meyer and Dennis Carlson. New York: Peter Lang.

Meyer, E. J., A. Tilland-Stafford, and L. Airton. 2016. "Transgender and gender-creative students in PK-12 schools: What we can learn from their teachers." Teachers College Record 118 (8):1-50.

Meyer, Elizabeth J. 2008. "A Feminist Reframing of Bullying and Harassment: Transforming Schools through Critical Pedagogy." McGill Journal of Education $43(1): 33-48$.

Orr, Asaf, and Joel Baum. 2015. "Schools in transition: A guide for supporting transgender students in K-12 schools." In, 61. San Francisco, CA: National Center for Lesbian Rights, Gender Spectrum, American Civil Liberties Union, National Education Association, and Human Rights Campain.

Rubin, Gayle. 1984/1993. "Thinking Sex: Notes for a Radical Theory of the Politics of Sexuality." In The Lesbian and Gay Studies Reader, edited by Henry Abelove, Michele Aina Barale and David M. Halperin, 3-44. New York: Routledge.

Rudoe, Naomi. 2010. "Lesbian teachers' identity, power and the public/private boundary." Sex Education 10 (1):23-36. doi: 10.1080/14681810903491347.

Sandeen, Autumn. 2014. "AB1266 petition drive fails." San Diego LGBT Weekly.

Scheurich, J. 1994. "Policy archeology: A new policy studies methodology." Journal of Education Policy 9 (4):297-316.

Serano, J. . 2007. Whipping girl: A transsexual woman on sexism and the scapegoating of femininity. Emeryville, CA: Seal Press.

SFUSD Student Family and Community Support Department. 2018. "LGBTQ Student Rights." San Francisco Unified School District, Accessed February 11, 2018. http://www.healthiersf.org/LGBTQ/GetTheFacts/lgbtqstudentRights.html. . 2018. "Transgender Policy." San Francisco Unified School District, Accessed Feburary 11, 2018. http://www.healthiersf.org/LGBTQ/GetTheFacts/poltransgender.html.

Slesaransky-Poe, G., L. Ruzzi, C. Dimedia, and J. Stanley. 2013. "Is this the right elementary school for my gender nonconforming child?" Journal of LGBT Youth 10 (1-2):29-44. doi: 10.1080/19361653.2012.718521.

Snorton, C.R. (2017). Black On Both Sides: A Racial History of Trans Identity. Minneapolis: University of Minnesota Press.

Spade, Dean. 2011. Normal Life: Administrative Violence, Critical Trans Politics, and the Limits of Law. Cambridge, MA: South End Press.

Spring, J. H. 2001. Deculturalization and the struggle for equality: A brief history of the education of dominated cultures in the United States. Boston: McGraw-Hill.

Stiegler, Sam. 2016. "Privacy for all students? Talking about and around trans students in "public"." Curriculum Inquiry 46 (4):348-68. doi:

10.1080/03626784.2016.1209638. 
Walton, Gerald. 2004. "Bullying and homophobia in Canadian schools: The politics of policies, programs, and educational leadership." Journal of Gay and Lesbian Issues in Education 1 (4):23-36.

. 2005. ""Bullying Widespread": A Critical Analysis of Research and Public Discourse on Bullying." Journal of School Violence 4 (1):91-118.

—. 2010. "The problem trap: implications of Policy Archaeology Methodology for anti-bullying policies." Journal of Education Policy 25 (2):135-50. doi: 10.1080/02680930903428630.

Wells, Kris, Gayle Roberts, and Carol Allan. 2012. Supporting Transgender and Transsexual students in K-12 Schools. Ottawa, ON: Canadian Teachers' Federation.

"Whitaker v. Kenosha Unified School District." In. 2017. U.S. Court of Appeals, Seventh Circuit.

11 Here, we will always be limited in our capacity to put into writing the many forms of language and expression that young people use to describe their bodies and identities. New terms are being developed each day, reflecting both the inadequacy of the currently dominant system of gender and the creativity of young people in subverting its norms. We primarily use the term "trans" and "transgender" as this is the language of the policy itself. For us, that term means the exponential and infinite ways that one might express their gender outside of a static, medicalized gender binary, and includes non-binary, gender-fluid, agender, genderqueer among other identities, but as we write in this article, that is not a definition that consistently aligns with policy.

2 Alabama, Georgia, Louisiana, Oklahoma, Tennessee, Texas, Utah, West Virginia, and Wisconsin as well as the Arizona Department of Education and Maine Governor Paul LePage

3 Arkansas, Kansas, Michigan, Montana, Nebraska, North Dakota, Ohio, South Carolina, South Dakota, Wyoming

4 "Biological sex" generally refers to the sex assigned to an individual at birth and noted on the birth certificate. There are various markers used in the medical community to determine biological sex, but the most commonly used one is the newborn child's external genitalia. For more extensive discussion on this please see (Fausto-Sterling 2000)

5 This was one of the first laws protecting LGBTQ students in K-12 schools, preceded only by Minnesota whose legislature amended the Minnesota Human Rights Act to include 'sexual 
orientation' in 1993. In Minnesota, 'sexual orientation' has been broadly defined5 to also include gender identity and expression.

6 There were subsequent attempts to repeal this law, including a signature drive to get a proposition on the ballot, but while the opposition group submitted enough signatures (619, 387 in total), 131,903 of those signatures failed to meet the verification test set by the state so they did not meet the minimum 504, 760 signatures required for ballot eligibility (Sandeen 2014) 